\title{
Erratum to: Genetic analysis of four European huchen (Hucho hucho Linnaeus, 1758) broodstocks from Poland, Germany, Slovakia, and Ukraine: implication for conservation
}

\author{
M. Kucinski ${ }^{1}$ - D. Fopp-Bayat ${ }^{1}$ - T. Liszewski ${ }^{1}$ • V. W. Svinger ${ }^{2} \cdot$ I. Lebeda $^{3} \cdot$ R. Kolman $^{4}$
}

Published online: 10 May 2017

(C) Institute of Plant Genetics, Polish Academy of Sciences, Poznan 2017

Erratum to: J Appl Genetics (2015) 56:469-480

DOI 10.1007/s13353-015-0274-9

The erratum concerns the information update on the finance support of the research published.

This study was supported by the projects No. GW/2013/12 (Optimization of PCR parameters of selected mitochondrial DNA fragments) and 2014/15/N/NZ9/01515 (Amplification of the microsatellite DNA fragments, genotyping and data analysis) financed by University of Warmia and Mazury in Olsztyn and National Science Centre, Poland.

The online version of the original article can be found at http://dx.doi.org/ 10.1007/s13353-015-0274-9.

M. Kucinski

marcin_kucinski1@o2.pl

1 Department of Ichthyology, University of Warmia and Mazury in Olsztyn, ul. Oczapowskiego 5, 10-719 Olsztyn, Poland

2 Fachberatung für Fischerei des Bezirks Oberfranken, Ludwigstraße, 20, 95444 Bayreuth, Germany

3 Faculty of Fisheries and Protection of Waters, University of South Bohemia in České Budějovice, 38925 Vodňany, Czech Republic

4 Department of Ichthyology, Inland Fisheries Institute in Olsztyn, 10-718 Olsztyn, Kortowo, Poland 